LBNL-58698

\title{
Preliminary Evaluation of Drift Seepage Model Using Seepage Information from the ESF South Ramp at Yucca Mountain, Nevada
}

\author{
Stefan Finsterle \\ Yongkoo Seol
}

Lawrence Berkeley National Laboratory

Berkeley, CA 94720

September, 2005

This work was supported, in part, by the Director, Office of Civilian Radioactive Waste Management, U.S. Department of Energy, through Memorandum Purchase Order QA-B004220RB3X between Bechtel SAIC Company, LLC and the Ernest Orlando Lawrence Berkeley National Laboratory (Berkeley Lab). The support is provided to Berkeley Lab through the U.S. Department of Energy Contract No. DE-AC02-05CH11231. 


\section{DISCLAIMER}

This document was prepared as an account of work sponsored by the United States Government. While this document is believed to contain correct information, neither the United States Government nor any agency thereof, nor The Regents of the University of California, nor any of their employees, makes any warranty, express or implied, or assumes any legal responsibility for the accuracy, completeness, or usefulness of any information, apparatus, product, or process disclosed, or represents that its use would not infringe privately owned rights. Reference herein to any specific commercial product, process, or service by its trade name, trademark, manufacturer, or otherwise, does not necessarily constitute or imply its endorsement, recommendation, or favoring by the United States Government or any agency thereof, or The Regents of the University of California. The views and opinions of authors expressed herein do not necessarily state or reflect those of the United States Government or any agency thereof, or The Regents of the University of California.

Ernest Orlando Lawrence Berkeley National Laboratory is an equal opportunity employer. 


\section{Table of Contents}

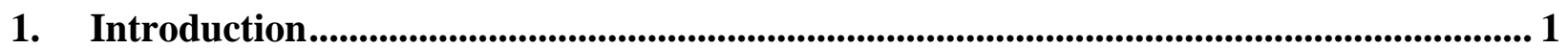

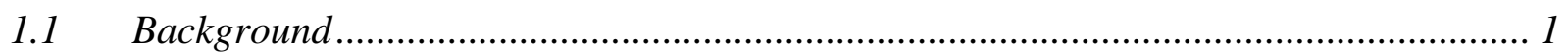

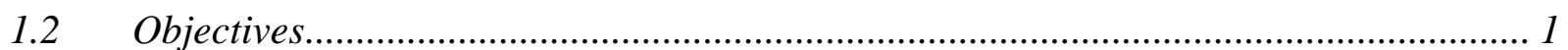

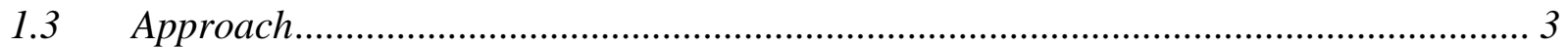

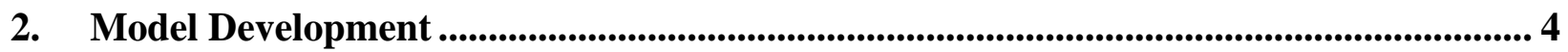

$2.1 \quad$ Model Geometry and Mesh Generation..................................................................... 4

$2.2 \quad$ Boundary and Initial Conditions ............................................................................ 5

2.3 Distributions of Seepage-Relevant Parameters.............................................................. 7

3. Seepage Simulations …................................................................................................................... 10

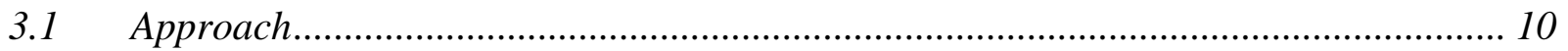

3.2 Generation of Seepage Response Surface ..................................................................... 11

3.3 Monte Carlo Simulations ...................................................................................... 12

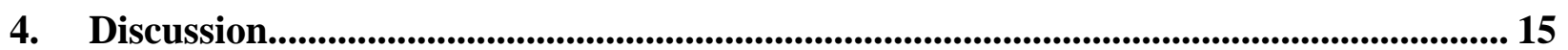

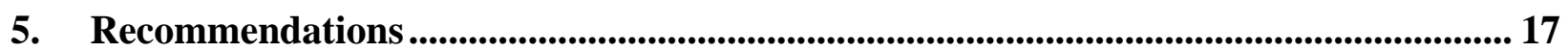

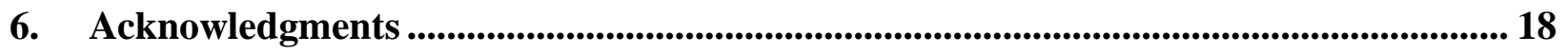

7. References .................................................................................................................................... 18 


\section{List of Figures}

Figure 1. Full periphery view of the ESF South Ramp from Station 75+00 to Station 78+00, showing seeps identified since February 29, 2005

Figure 2. South Ramp as-built cross section and seepage areas observed during spring 2005.

Figure 3. Model domain and mesh design for South Ramp seepage simulation ....................... 4

Figure 4. Total monthly rainfall during Oct. 2004 to Feb. 2005, the conjectured infiltration, and surface infiltration on top of South Ramp for present-mean infiltration scenario.

Figure 5. Calculated average seepage flux into 5-m long section of ESF between October 2004 and February 2005 as a function of the three seepage-relevant parameters permeability, capillary strength and local percolation flux (expressed as a fraction of precipitation).

Figure 6. Histograms of seepage-relevant input parameters obtained by Latin Hypercube sampling.

Figure 7. Seepage flux from 1000 transient simulations using Latin Hypercube sampling of seepage-relevant parameters.

Figure 8. Cumulative distribution function of seepage flux averaged over the 5-month simulation period. Approximately $86 \%$ of the realizations did not yield any seepage; $5 \%$ of the realizations yielded seepage fluxes greater than approximately $11 \mathrm{~mm} / \mathrm{yr}$ 


\section{List of Tables}

Table 1. Base-case monthly infiltration fluxes.......................................................... 6

Table 2. Fracture permeabilities from various sources for selected Tiva Canyon and Topopah Spring units and the estimated fracture permeability for seepage simulations in the ESF South Ramp ................................................................ 9

Table 3. Seepage-relevant parameters …..................................................................... 9

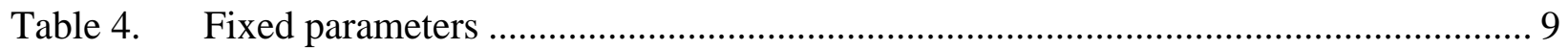




\section{INTENTIONALLY LEFT BLANK}




\section{INTRODUCTION}

\subsection{Background}

During the period between October 2004 and February 2005, unusually heavy precipitation (12.75 inches, which is about 3.5 times the recent nine-year average of 3.64 inches, taken over the same time period between October and February) occurred in the Yucca Mountain area. On February 28, 2005, Yucca Mountain Project personnel working in the South Ramp of the Exploratory Studies Facility (ESF) observed-in select areas-wet spots on the main drift's crown, ribs, and invert. This field observation is considered the first unambiguous evidence of seepage under ambient conditions.

As shown in Figure 1, wet areas were identified between Stations $75+62$ and 75+82, Stations 75+92 and 76+07, and Stations 77+48 to 77+53. The section of the ESF South Ramp that is located in the densely welded, pervasively fractured rocks of the Tiva Canyon Tuff-i.e., where there are no intervening layers of bedded or non-welded tuffs (PTn) between the main drift and the surface-is approximately $300 \mathrm{~m}$ long, from Station $75+80$ to the South Portal at Station 78+77 (Figure 2).

Assuming (1) that each of the wet areas identified in Figure 1 actually resulted in drop formation and drop detachment (as opposed to film flow along the drift surface), and (2) that-for wet areas extending more than $5 \mathrm{~m}$ in axial direction—at least one dripping location exists for every 5 meters of continuous wet area, it can be estimated that approximately $13 \%$ of the drift section experienced seepage. Note that the actual drip area is substantially smaller than the wet area; however, given the assumptions outlined above, this does not affect the calculation of the seepage percentage as defined in the Total System Performance Assessment for License Application (TSPA-LA).

\subsection{Objectives}

The overall objective of this study is to examine whether the modeling approach employed to estimate seepage into waste emplacement drifts yields results that are consistent with the observed seepage in the ESF South Ramp.

It is important to realize that the modeling study reported here is not an attempt to predict, reproduce, or analyze the South Ramp seepage data. Such an effort would require the development of a specific model and a specific characterization and analysis approach best suited for capturing the hydrogeologic conditions in the South Ramp as they prevailed before and during the period of the seepage observations. Instead, the conceptual framework and analysis approach developed for the estimation of long-term seepage into waste emplacement drifts in the Topopah Spring unit is used with minimal adjustments to examine whether the results of the probabilistic approach employed in the TSPA-LA (which considers uncertainty and spatial variability in fracture permeability, capillary strength, and local percolation flux) would provide reasonable seepage estimates, even if applied to the conditions in the South Ramp. If so, confidence can be gained that the TSPA-LA approach captures the processes relevant for the prediction of natural seepage into large underground openings. 


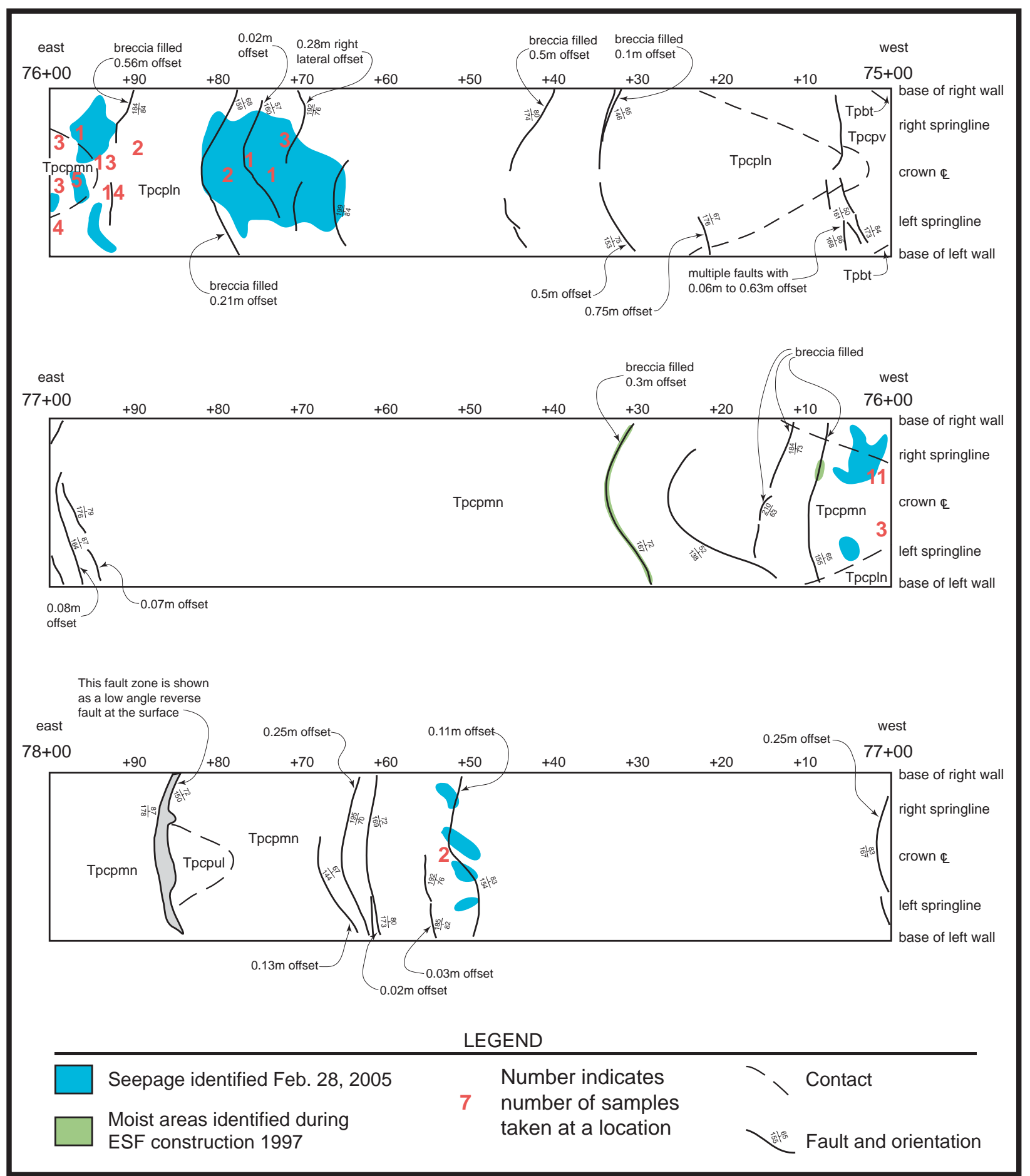

NOTE: Geology is taken from full periphery maps OA-46-282, -293, and -294 (DTN: GS970808314244.013). Normal offset is noted for most faults; however, the fault zone at $78+85$ has been interpreted to be a lowangle reverse fault at the surface.

SOURCE: BSC (2005)

Figure 1. Full periphery view of the ESF South Ramp from Station $75+00$ to Station $78+00$, showing seeps identified since February 28, 2005. 


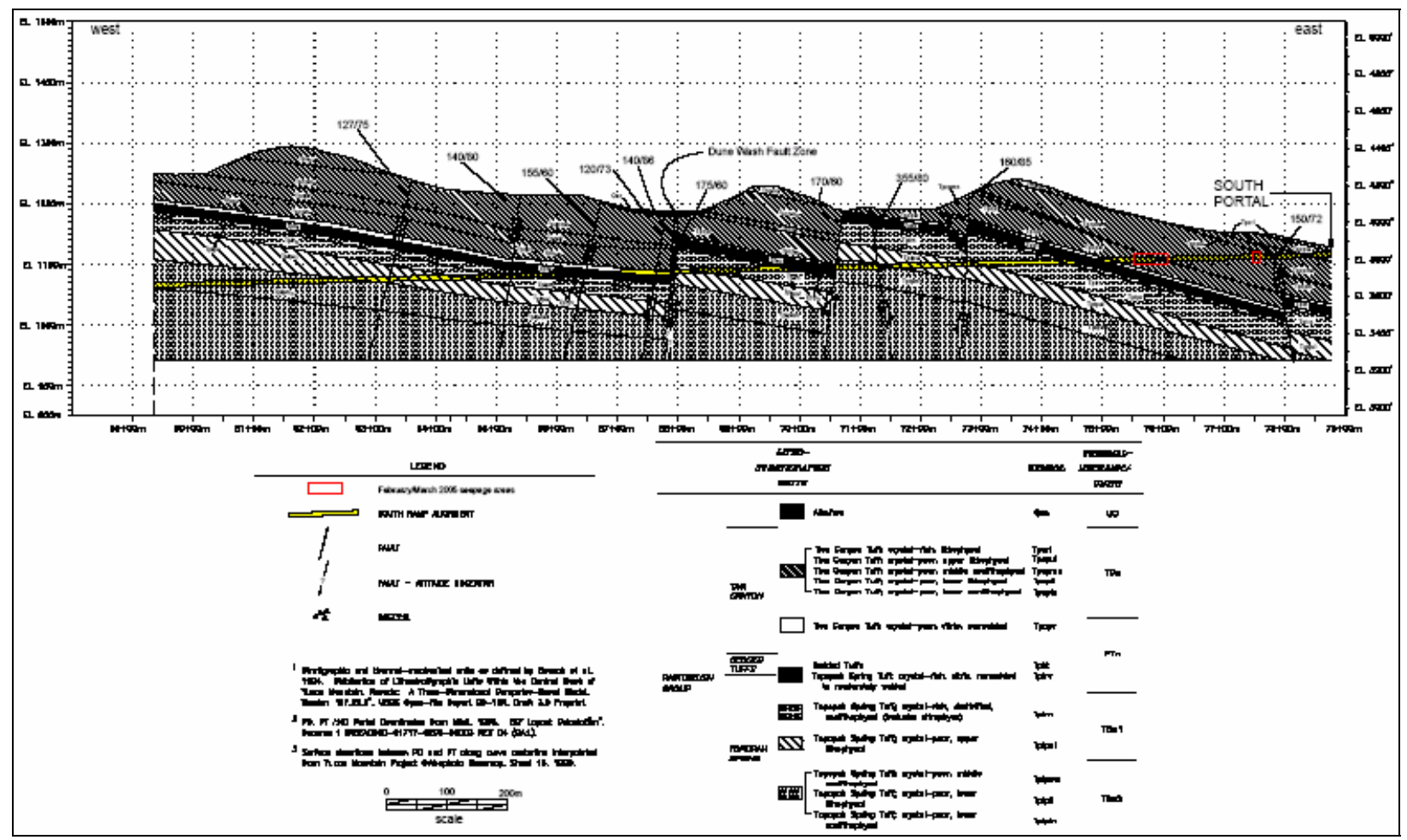

NOTE: $\quad$ Modified from drawing OA-46-301, DTN: GS970808314224.016, MOL.19980127.0397

Figure 2. South Ramp as-built cross section and seepage areas observed during spring 2005.

\subsection{Approach}

The approach closely follows that described in the reports Seepage Model for PA Including Drift Collapse (BSC 2004a) and Abstraction of Drift Seepage (BSC 2004b):

- Develop a heterogeneous fracture-continuum model of a 5-m long section of the ESF.

- Evaluate seepage for a range of parameter values. The three seepage-relevant parameters varied are (1) reference fracture permeability, (2) van Genuchten capillarystrength parameter, and (3) average percolation flux at top model boundary.

- Develop look-up table of seepage as a function of the three seepage-relevant parameters. (Note that the look-up table developed here is based on a single realization of the underlying heterogeneous fracture permeability field, whereas multiple realizations were calculated by the SMPA.)

- Determine probability distributions for the three seepage-relevant parameters.

- Randomly sample from the probability distributions and determine related seepage flux (either by interpolation from the seepage look-up table, or by performing Monte Carlo simulations using the process model directly).

- Determine seepage fraction (percentage of realizations with non-zero seepage).

- Relate modeling results to qualitative information from seepage observations in ESF South Ramp. 


\section{MODEL DEVELOPMENT}

\subsection{Model Geometry and Mesh Generation}

A three-dimensional (3D) model for calculating seepage into the South Ramp is developed based on the Seepage Model for Performance Assessment (SMPA) (BSC 2004a) by adjusting the drift diameter to $8 \mathrm{~m}$, which requires increasing the width of the domain to $5.55 \mathrm{~m}, 1.5 \mathrm{~m}$ wider than that of the SMPA; the length and height are left unchanged at 8 feet $(2.4384 \mathrm{~m})$ and $10.0 \mathrm{~m}$, respectively. Due to symmetry, a drift section half the length of a typical waste package is modeled, and only the left-hand half of the ESF drift is represented (Figure 3). Since seepage is only expected from the upper half of the drift, the lower boundary of the model is set $0.5 \mathrm{~m}$ below the drift axis.

The model domain is discretized as follows. The length along the drift axis consists of 8 grid cells of 1 foot $(0.3048 \mathrm{~m})$ length. The grid cells in the plane normal to the drift axis are of dimensions $0.1 \mathrm{~m} \times 0.1 \mathrm{~m}$. This grid resolution is identical to that of the SMPA. The grid was generated using the script files presented in Appendix C of the report Seepage Calibration Model and Seepage Testing Data (BSC 2004c), slightly modified to accommodate the larger drift size. The script files generate the 3D mesh by (1) generating a cubic mesh of the domain with the specified discretization, (2) mapping a field of permeability modifiers onto the mesh, (3) cutting a cylindrical drift from this cubic mesh, while inserting an element representing the drift, and (4) adding extra top and bottom boundary elements.

Seepage flux will be calculated by the total amount of water entering the drift element, divided by the footprint area of the drift, i.e., half the drift diameter times the length, which amounts to an area of $(8 / 2) \times 2.4384=9.7536 \mathrm{~m}^{2}$.

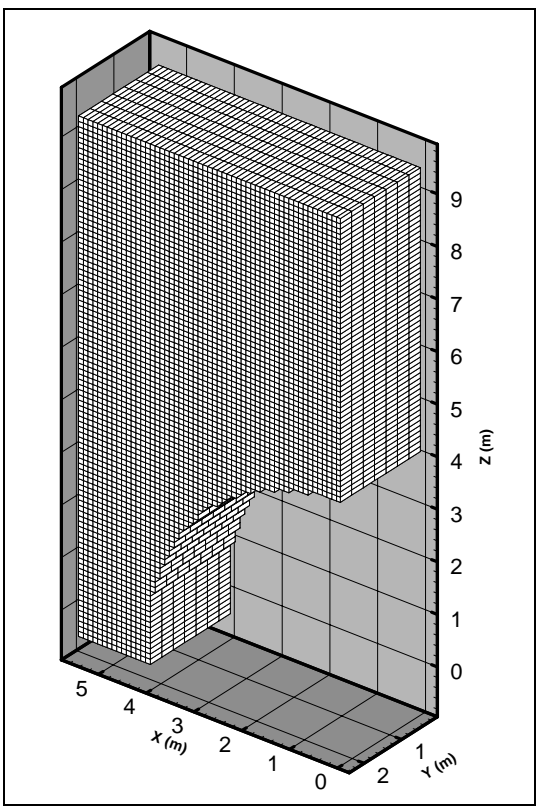

Figure 3. Model domain and mesh design for South Ramp seepage simulation 


\subsection{Boundary and Initial Conditions}

The following boundary conditions are specified.

- No-flow boundary conditions are specified at the left, right, front, and back sides of the model.

- A free-drainage boundary condition is applied at the bottom to prevent an unphysical capillary boundary effect.

- The elements representing the ESF are assigned a zero-capillary pressure independent of saturation, which is equivalent to assuming $100 \%$ relative humidity in the ESF. This assumption (while consistent with that in the SMPA), may not be representative of the conditions in the ESF. Including evaporation effects in the model would reduce the calculated seepage rate and seepage percentage.

- A time-dependent flux boundary condition at the top of the model needs to be specified. This flux will represent the local percolation flux $6 \mathrm{~m}$ above the crown of the ESF. In the absence of direct percolation flux measurements, the flux is usually estimated based on precipitation data, which are used to estimate net infiltration, followed by a calculation of unsaturated flow through the Tiva Canyon unit. For this preliminary seepage study, no detailed infiltration and percolation calculations are available. The following values are specified:

- A long-term infiltration flux is specified to obtain the initial background flow field. A value of $4.2 \mathrm{~mm} / \mathrm{yr}$ is applied, taken from the infiltration map (column a23) used by the Unsaturated Zone (UZ) Flow Model (BSC 2004d) for present-day conditions.

- Increased precipitation between October 2004 and February 2004 preceded the seepage observations in the South Ramp. The long-term and monthly precipitation averages are summarized in Table 1 and Figure 4. In the absence of a detailed infiltration analysis, infiltration is assumed to be on the order of $10 \%$ of precipitation. (Note that the net infiltration index is generally described as a power function of precipitation.)

- The local percolation flux is inferred from the net infiltration flux, assuming that unsaturated flow in the Tiva Canyon unit is (on the scale of the length of the South Ramp) predominantly vertical. However, flow focusing effects as discussed in Section 6.8 of BSC (2004a) may reduce and enhance the local percolation flux compared to the infiltration flux.

- Local percolation fluxes directly inferred from precipitation data are considered highly uncertain. The high rainfalls may lead to higher runoff, potentially reducing the ratio between infiltration and precipitation. On the other hand, evapotranspiration may be reduced compared to the annual average, leading to a higher ratio.

- Spatial and temporal rainfall patterns affect infiltration and percolation flux distributions. Multiplication factors describing focusing and redistribution of flow are not known.

- To account for this uncertainty and flow focusing effects, and in the absence of detailed analyses of infiltration, percolation, and flow focusing, seepage is evaluated for local percolation fluxes ranging from essentially $0 \%$ to approximately $40 \%$ of the monthly precipitation flux (see Figure 6 below). 
Table 1. Base-case monthly infiltration fluxes

\begin{tabular}{lcc}
\hline \multicolumn{1}{c}{ Month } & $\begin{array}{c}\text { Measured } \\
\text { Precipitation Flux } \\
{[\mathrm{mm} / \mathrm{yr}]}\end{array}$ & $\begin{array}{c}\text { Assumed Base- } \\
\text { Case Infiltration } \\
\text { Flux }{ }^{\mathrm{a}}[\mathrm{mm} / \mathrm{yr}]\end{array}$ \\
\hline Long-term & 188.5 & 4.2 \\
October & 814.0 & 81.4 \\
November & 392.7 & 39.3 \\
December & 574.6 & 57.5 \\
January & 864.9 & 86.5 \\
February & 1308.8 & 130.9 \\
\hline a Base-case infiltration is assumed 10\% of the monthly averaged \\
precipitation; long-term infiltration is taken from the UZ Flow Model \\
(BSC 2004d)
\end{tabular}

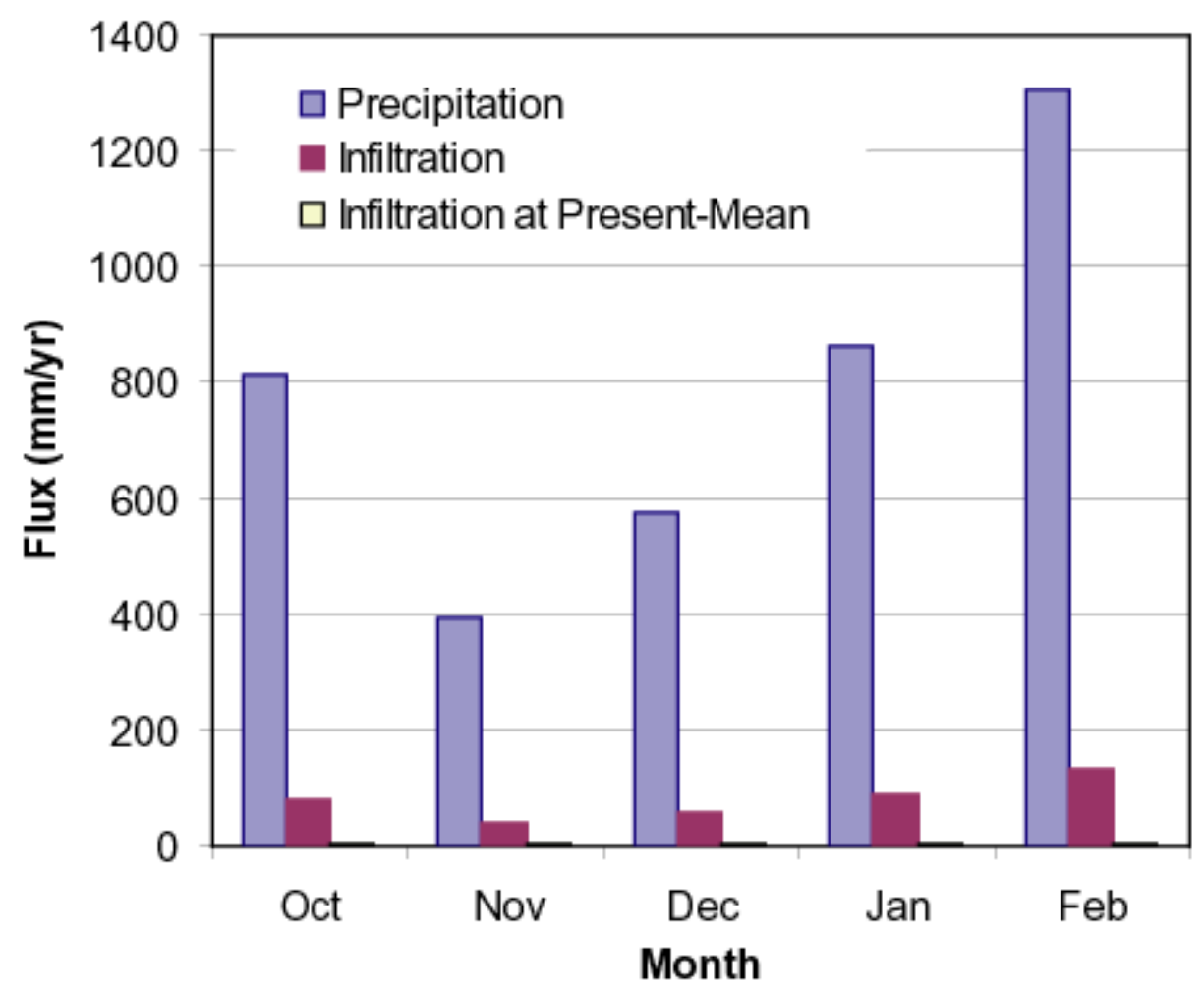

Figure 4. Total monthly rainfall during Oct. 2004 to Feb. 2005, the conjectured infiltration, and surface infiltration on top of South Ramp for present-mean infiltration scenario. 


\subsection{Distributions of Seepage-Relevant Parameters}

The following three uncertain model parameters have been identified as significantly affecting seepage:

- Mean fracture-continuum permeability $\log \left(k_{f}\left[\mathrm{~m}^{2}\right]\right)$

- van Genuchten capillary-strength parameter $1 / \alpha[\mathrm{Pa}]$

- Local percolation flux $q_{f}[\mathrm{~mm} / \mathrm{yr}]$ applied at top model boundary

Following the approach outlined in the seepage abstraction (BSC 2004b), probability distributions need to be defined for these three seepage-relevant parameters to account for their respective uncertainty and spatial variability; they are summarized in Table 2 and discussed below.

The fracture permeability determines the ease with which water is diverted around the capillary barrier acting at the drift surface. The higher the permeability, the smaller the seepage rate for a given capillary strength and percolation flux. The base-case, mountain-scale log-permeability values $\left[\log _{10} \mathrm{~m}^{2}\right]$ of the Tiva Canyon middle nonlithophysal (Tpcpmn, tcw12) and the lower nonlithophysal (Tpcpln, tcw13) units were estimated by calibration against pneumatic pressure data to be -10.02 and -10.87 , respectively (BSC 2004f), which yields an approximate average of -10.5. Due to the large scale and preferential weighting of high-permeability features, this estimate is considered high and not representative of drift-scale conditions needed for seepage calculations. Air permeabilities from surface-based borehole data are significantly smaller in both the Tiva Canyon and Topopah Spring units (see Table 2). Pre-excavation, small-scale airpermeability data from the Topopah Spring unit suggest drift-scale permeabilities that are more than 1.5 orders of magnitude smaller than the mountain-scale permeabilities. However, dilation effects as a result of drift excavation may increase the pre-excavation permeabilities by 1.3 orders of magnitude for the relatively low-permeable Tptpmn unit, and 0.7 orders of magnitude for the Tptpll unit, which has a higher undisturbed permeability.

To estimate the seepage-relevant small-scale permeability of the excavation-disturbed zone around the ESF in the Tiva Canyon unit, we start with the log-permeability of -11.3, measured from surface-based boreholes. Following the analysis of permeability data from the Topopah Spring unit, we then adjust the value, reducing it by one order of magnitude to account for scale effects, and increasing it by 0.8 orders of magnitude to include excavation effects.

In summary, for this preliminary seepage modeling, the mean fracture permeability is assumed to follow a log-normal distribution with a mean for $\log \left(k_{f}\left[\mathrm{~m}^{2}\right]\right)$ of -11.5 and a standard deviation of 1.0. The distribution is truncated to yield a range between -13.5 and -9.5 . Note that the seepage abstraction (BSC 2004b, Section 6.6.3) uses a triangular and normal distribution to characterize, respectively, uncertainty and variability in log-permeability. Also note that this distribution represents the uncertainty and variability of the mean permeability on the drift scale (i.e., approximately the size of a 5-m long drift segment). Small-scale heterogeneity is explicitly accounted for by generating a random permeability field around this drift-scale mean, using a standard deviation of 1.0 and a correlation length of $0.3 \mathrm{~m}$ (see Table 4). 
The van Genuchten capillary-strength parameter $1 / \alpha$ characterizes the strength of the fracture network to retain the water within the formation, reducing or preventing seepage. The capillarystrength parameter determined by calibration against matrix saturation data for the Tiva Canyon layers ranges from 313 to $809 \mathrm{~Pa}$, depending on the infiltration scenario (BSC 2004f, Tables 6-8, 6-9, and 6-10). A seepage-related capillary-strength parameter was experimentally determined through inverse modeling of seepage testing data for the Topopah Spring Welded Tuff units (Tptpll and Tptpmn; BSC 2004a, Section 6.6.4). The seepage abstraction determined a mean value of $591 \mathrm{~Pa}$ and reported a range from $297 \mathrm{~Pa}$ to $885 \mathrm{~Pa}$. As discussed in BSC (2004b, Section 6.3.3.2), the capillary-strength parameter to be used for seepage simulations is an effective parameter, which specifically accounts for features and processes that affect seepage. Since many of these features and processes (such as surface roughness effects and film flow along the drift wall) are lumped into the effective capillary-strength parameter during model calibration, this parameter does not strongly depend on the hydrogeologic unit. It is therefore reasonable to employ a similar range for the study of seepage in the Tiva Canyon unit. A normal distribution for $1 / \alpha$ was chosen, with a mean, standard deviation, and range of $591 \mathrm{~Pa}, 100 \mathrm{~Pa}$, and $300-900 \mathrm{~Pa}$, respectively. Note that the seepage abstraction (BSC 2004b, Section 6.6.2) uses a triangular and uniform distribution to characterize, respectively, uncertainty and variability of the capillary-strength parameter.

The amount of water arriving at the drift critically determines seepage. Specifically, if the local percolation flux is below the so-called seepage threshold, no seepage will occur. The percolation flux as imposed at the upper boundary of the model domain is considered the third seepagerelevant parameter. To account for uncertainty in precipitation, infiltration, and flow redistribution between the land surface and the South Ramp within the Tiva Canyon unit, the time-dependent, precipitation fluxes as specified in Table 1 are multiplied by a normally distributed factor that has a mean of 0.1 and a standard deviation of 0.1 . To avoid unreasonable local percolation fluxes during Monte Carlo sampling, the normal distribution is truncated by rejecting factors smaller than 0.01 and factors greater than 1.0. Note that this approach is different from that employed in TSPA-LA, where the local percolation flux is taken from the Multiscale Thermohydrologic Model and multiplied by a flow focusing factor, which is randomly sampled from a (non-Gaussian) flow focusing factor distribution.

Additional parameters affecting unsaturated flow and seepage processes are considered of less significance and are thus fixed at the values given in Table 4 . 
Table 2. Fracture permeabilities from various sources for selected Tiva Canyon and Topopah Spring units and the estimated fracture permeability for seepage simulations in the ESF South Ramp

\begin{tabular}{|l|c|c|c|}
\hline Source & $\begin{array}{c}\text { Tiva Canyon } \\
\left.\log \left(\mathbf{k} \mathbf{m}^{2}\right]\right)\end{array}$ & $\begin{array}{c}\text { Topopah Spring } \\
(\mathbf{T p t p m n}) \\
\log \left(\mathbf{k}\left[\mathbf{m}^{2}\right]\right)\end{array}$ & $\begin{array}{c}\text { Topopah Spring } \\
(\mathbf{T p t p l l}) \\
\log _{\left(\mathbf{k}\left[\mathbf{m}^{2}\right]\right)}\end{array}$ \\
\hline Calibrated with Pneumatic Data & $-10.5^{\mathrm{a}}$ & $-10.5^{\mathrm{a}}$ & $-10.0^{\mathrm{a}}$ \\
\hline Surface-Based Borehole Data & $-11.3^{\mathrm{b}}$ & $-12.2( \pm 0.34)^{\mathrm{c}}$ & - \\
\hline $\begin{array}{l}\text { Small-Scale Air-Injection Test } \\
\text { (Pre-Excavation) }\end{array}$ & $\mathbf{- 1 2 . 3 ^ { \mathrm { e } }}$ & $-13.2( \pm 0.85)^{\mathrm{d}}$ & $-11.5( \pm 1.12)^{\mathrm{d}}$ \\
\hline $\begin{array}{l}\text { Small-Scale Air-Injection Test } \\
\text { (Post-Excavation) }\end{array}$ & $\mathbf{- 1 1 . 5 ^ { \mathrm { e } }}$ & $-11.9( \pm 0.79)^{\mathrm{d}}$ & $-10.8( \pm 1.31)^{\mathrm{d}}$ \\
\hline
\end{tabular}

NOTE: ${ }^{a}$ Based on Calibrated Properties Model (BSC 2004), Table 6-12, DTN: LB02091DSSCP3I.002

${ }^{\mathrm{b}}$ Analysis of Hydrologic Properties Data (BSC 2004), Table 6, DTN: LB0205REVUZPRP.001

${ }^{c}$ Abstraction of Drift Seepage (BSC 2004), Table 6.6-5 DTN: LB0407AMRU0120.001

${ }^{d}$ Abstraction of Drift Seepage (BSC 2004), Table 6.6-3 DTN: LB0407AMRU0120.001

${ }^{\mathrm{e}}$ Inferred from available data in the Topopah Spring unit.

Table 3. Seepage-relevant parameters

\begin{tabular}{|l|l|c|c|c|c|}
\hline \multicolumn{1}{|c|}{ Parameter } & \multicolumn{1}{|c|}{ Distribution } & Mean & $\begin{array}{l}\text { Standard } \\
\text { Deviation }\end{array}$ & Lower Bound & Upper Bound \\
\hline $\begin{array}{l}\text { Drift-scale } \\
\text { fracture } \\
\text { permeability }\end{array}$ & Lognormal & -11.5 & 1.0 & -13.5 & -9.5 \\
\hline $\begin{array}{l}\text { Capillary- } \\
\text { strength } \\
\text { parameter }\end{array}$ & Normal & 591 & 100 & 300 & 900 \\
\hline $\begin{array}{l}\text { Percolation } \\
\text { index }\end{array}$ & Normal & 0.1 & 0.1 & 0.01 & 1.0 \\
\hline
\end{tabular}

Table 4. Fixed parameters

\begin{tabular}{|l|c|}
\hline \multicolumn{1}{|c|}{ Parameter } & Value \\
\hline Fracture porosity [-] & $0.015^{\mathrm{a}}$ \\
\hline Residual liquid saturation [-] & $0.01^{\mathrm{a}}$ \\
\hline Satiated saturation [-] & $1.00^{\mathrm{a}}$ \\
\hline van Genuchten parameter $m[-]$ & $0.633^{\mathrm{a}}$ \\
\hline van Genuchten parameter $n=1 /(1-m)[-]$ & 2.72 \\
\hline Geostatistical parameters for small-scale & \\
distribution of fracture permeability: & \\
Variogram type & Spherical \\
Standard deviation log $\left(k\left[\mathrm{~m}^{2}\right]\right)$ & $1.0^{\mathrm{b}}$ \\
Correlation length $[\mathrm{m}]$ & $0.3^{\mathrm{b}}$ \\
\hline
\end{tabular}

a Source: BSC (2004f), Table 4-3

b Source: BSC (2004a), Section 6.3 


\section{SEEPAGE SIMULATIONS}

\subsection{Approach}

Two sets of simulations are performed using iTOUGH2 V 5.0 (LBNL 2002 [DIRS 160106]) on a Linux cluster:

- Seepage is evaluated for many combinations of the three seepage-relevant parameters (drift-scale fracture-continuum permeability, capillary-strength parameters, and local percolation flux) to generate a seepage response surface (look-up table)

- Monte Carlo simulations are performed to estimate the likelihood of observing seepage in the South Ramp

In both approaches, individual simulations calculate the seepage flux (defined as the flow rate into the opening divided by the footprint area of the ESF drift section) for a given parameter set. In the first approach, which can be considered an extensive sensitivity analysis, the parameter space is examined systematically within the range given in Table 3. A response surface can be interpolated between the discrete points evaluated by the process model, providing the seepage flux for all possible parameter combinations; it also reveals the seepage threshold. However, it does not provide information about the likelihood that seepage occurs.

In order to obtain the seepage fraction (i.e., the number of 5-m long drift sections that are likely to encounter a non-zero seepage flux), information about the probability of the three seepagerelevant parameters is required. The approach implemented in TSPA-LA is described in the report Abstraction of Drift Seepage (BSC 2004b). Here, a simple Monte Carlo analysis is performed for the same purpose. It must be realized that distributions used for the Monte Carlo simulations described here (see Table 3) are different from those proposed by the seepage abstraction and used by TSPA-LA. Furthermore, the TSPA-LA approach is more complex and includes multiple scenarios and seepage prediction uncertainty that are not considered in this preliminary analysis. Nevertheless, the Monte Carlo approach chosen here can be considered an alternative, reasonable attempt at estimating seepage into the ESF South Ramp.

Each individual simulation of unsaturated flow and seepage for a given parameter set consists of two parts. First, a steady-state simulation is performed using the long-term, present-day percolation flux of $4.2 \mathrm{~mm} / \mathrm{yr}$. The resulting flow field is used as the initial condition for the subsequent simulation of the high-precipitation events during the period between October 2004 and February 2005, where monthly averages (see Table 1) are multiplied by a truncated, normally distributed number between 0.01 and 1.0 (with mean 0.1 and standard deviation of 0.1 ); the resulting local percolation flux is then applied at the top of the model. The amount of seepage into the ESF drift section is calculated, divided by the footprint of the modeled drift section, and averaged over the period of 5 months to yield the seepage flux reported below. (Note that transient seepage fluxes are available; the results are averaged over the 5-months period to yield a result that can easily be reported. Assuming that no additional seepage will occur during the remainder of the year, the seepage rate values could be multiplied by a factor of 5/12 to yield annual averages, which are then comparable to the long-term average fluxes visualized in Figure 6-4 of BSC (2004a). 


\subsection{Generation of Seepage Response Surface}

Predictive simulations for seepage were performed systematically for combinations of seepagerelevant parameters. The three-dimensional parameter space was subdivided into $8 \times 8 \times 8$ equally spaced points over the parameter's respective ranges (see Table 3). For each of the 512 parameter combinations, a steady-sate simulation was performed with the long-term percolation flux of $4.2 \mathrm{~mm} / \mathrm{yr}$, followed by a transient simulation to capture the response of the system to the high precipitation between October 2005 and February 2005. The total seepage entering a 5-m long segment of the ESF during this 5-month period was recorded, and the corresponding average flux was calculated and plotted (see Figure 5).

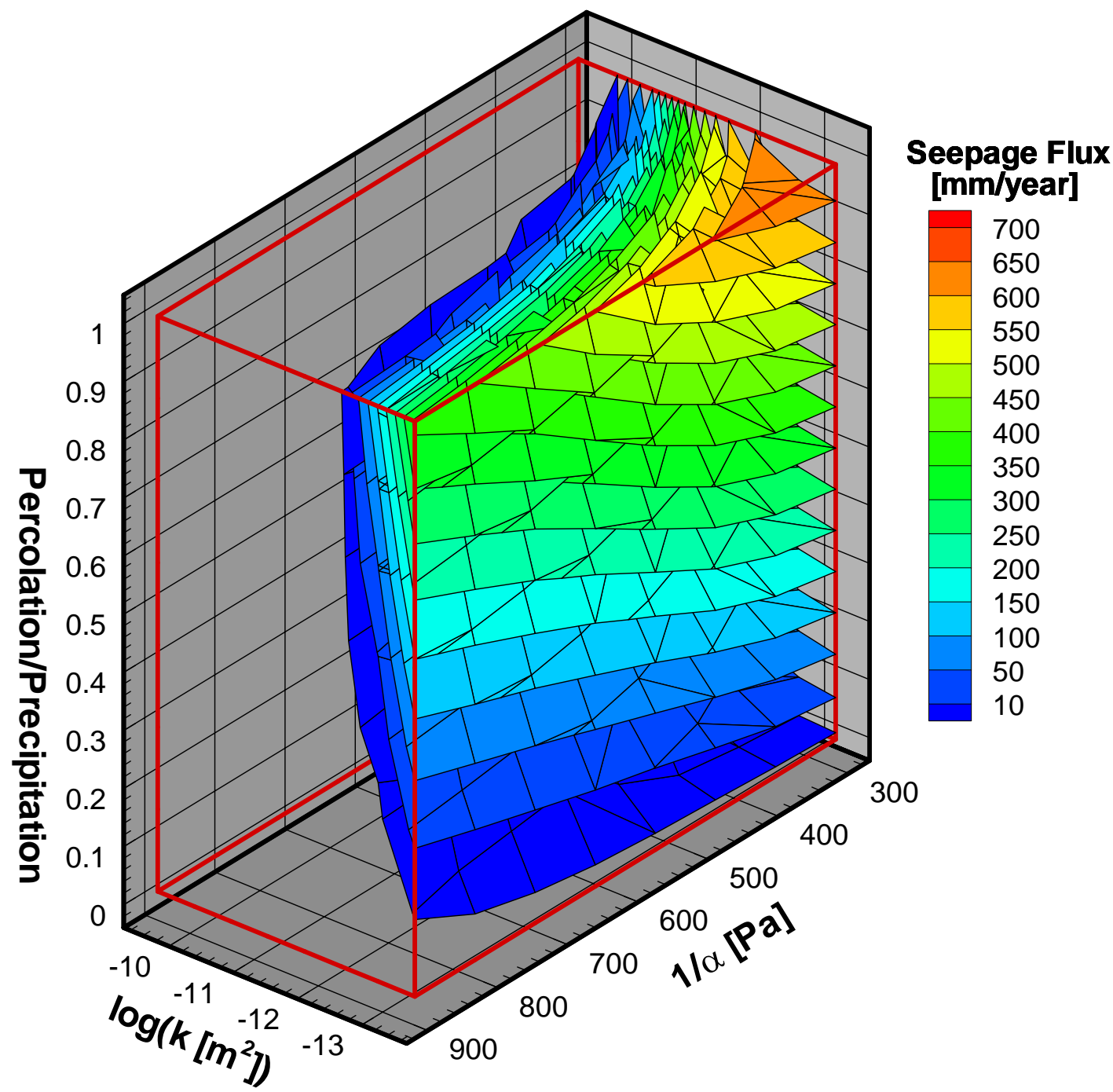

Figure 5. Calculated average seepage flux into 5-m long section of ESF between October 2004 and February 2005 as a function of the three seepage-relevant parameters permeability, capillary strength and local percolation flux (expressed as a fraction of precipitation). 
For any given combination of seepage-relevant parameters that may be encountered along the ESF South Ramp, the look-up table visualized in Figure 5 can be used to determine whether seepage is expected to occur, and what the corresponding seepage rate is. No seepage is expected for locations with high permeability and high capillary strength. For low-permeability sections in the South Ramp, seepage into the ESF is expected even for small local percolation rates. Significant seepage is expected if capillarity is week and the local percolation flux is high.

\subsection{Monte Carlo Simulations}

As discussed in Section 3.1, Figure 5 (or the underlying look-up table) can be used in a probabilistic calculation to evaluate the seepage probability in the ESF South Ramp. In such an approach, the three seepage-relevant parameters are repeatedly sampled from their respective uncertainty and variability distributions, and the corresponding seepage flux is interpolated from the look-up table. The resulting frequency distribution of the seepage flux contains the desired information. Specifically, the fraction of realizations yielding non-zero seepage rates can be interpreted as the expected percentage of 5-m long drift sections that encounter seepage.

Instead of interpolating from the look-up table, we calculated the seepage flux using the seepage process model directly. A Latin Hypercube sampling strategy was used, generating 1000 uncorrelated parameter sets that follow the predefined probability distributions of Table 3 . The histograms of the generated input parameters are shown in Figure 6, with the subset of realizations that led to seepage shown as shaded histograms. As expected, only locations with a log-permeability of less than -12 resulted in seepage; the probability of encountering a location in that permeability range is assumed to be approximately 35\%. Locations with a relatively weak capillary-strength parameter are more likely to induce seepage, as expected. Nevertheless, seepage was predicted for $1 / \alpha$ values as high as $780 \mathrm{~Pa}$, if combined with a relatively low permeability and relatively high percolation flux. While high percolation fluxes naturally lead to seepage, in $50 \%$ of the cases seepage was induced at locations with a percolation index of less than about 0.17 .

The resulting realizations of seepage into a 5-m long drift section are shown in Figure 7. The time-dependent seepage flux reflects the changing precipitation conditions at the land surface. The relatively fast response of seepage to changes in precipitation is a result of the fact that matrix imbibition effects are ignored in the current model, because the model was developed for steady-state simulations.

The cumulative frequency distribution of the seepage flux averaged over the 5-month simulation period is shown in Figure 8. Of the 1000 simulations, 128 (or 12.8\%) yielded non-zero seepage, and there is a 5\% probability that a 5-m long drift section experiences a 5-month average seepage flux of at least $18 \mathrm{~mm} / \mathrm{yr}$, which corresponds to an average rate of approximately $80 \mathrm{~mL} / \mathrm{hr}$. Such a rate is within the range $(4.5-125 \mathrm{~mL} / \mathrm{hr}$ ) measured during water sampling (BSC 2005, Section 2.2).

Within the current framework, these probabilities for seepage at a given location can also be interpreted (assuming ergodicity) as the fraction of drift sections that experiences seepage. For the $300 \mathrm{~m}$ long ESF South Ramp section that is not overlain by the PTn unit, these preliminary 
results suggest that seepage would have been observed over a total distance of approximately 38 $\mathrm{m}$; this value (while highly uncertain — see discussion in Section 4) is not inconsistent with the actually observed extent of wet areas in the ESF South Ramp of approximately $40 \mathrm{~m}$ (see Figure 1 and related discussion).
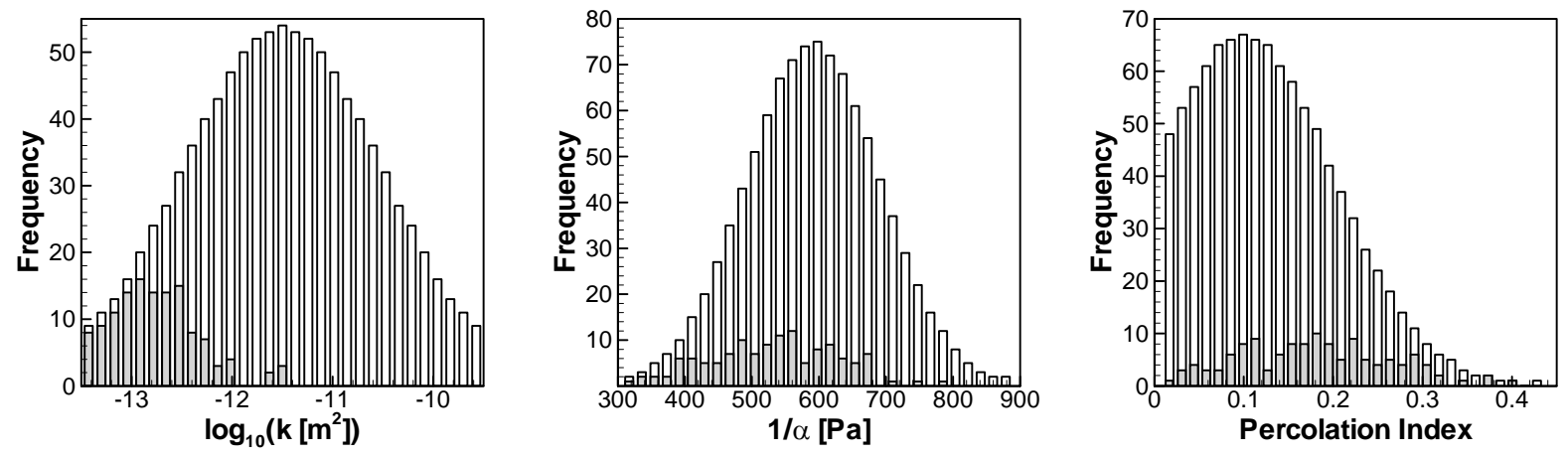

Figure 6. Histograms of seepage-relevant input parameters obtained by Latin Hypercube sampling. The parameter realizations that led to seepage are shown as shaded histograms.

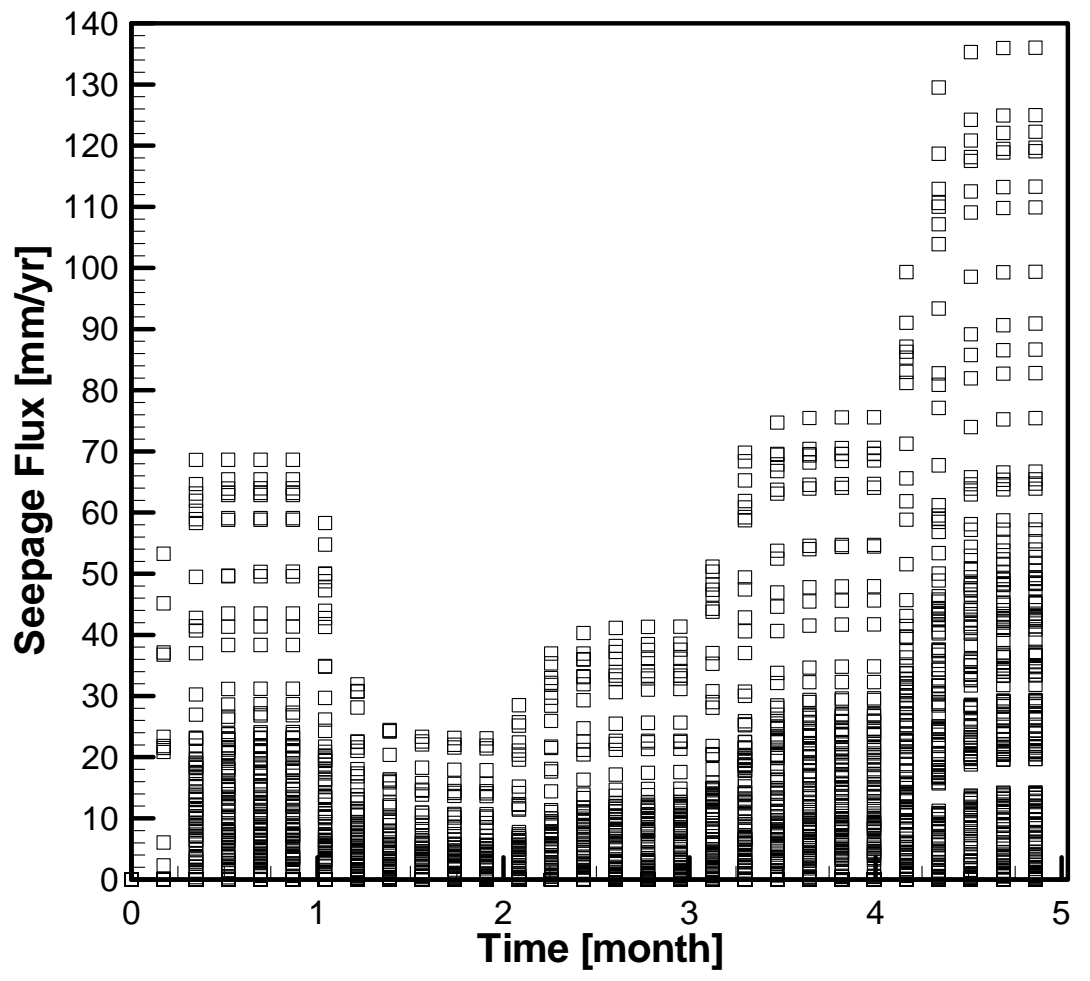

Figure 7. Seepage flux from 1000 transient simulations using Latin Hypercube sampling of seepagerelevant parameters. 


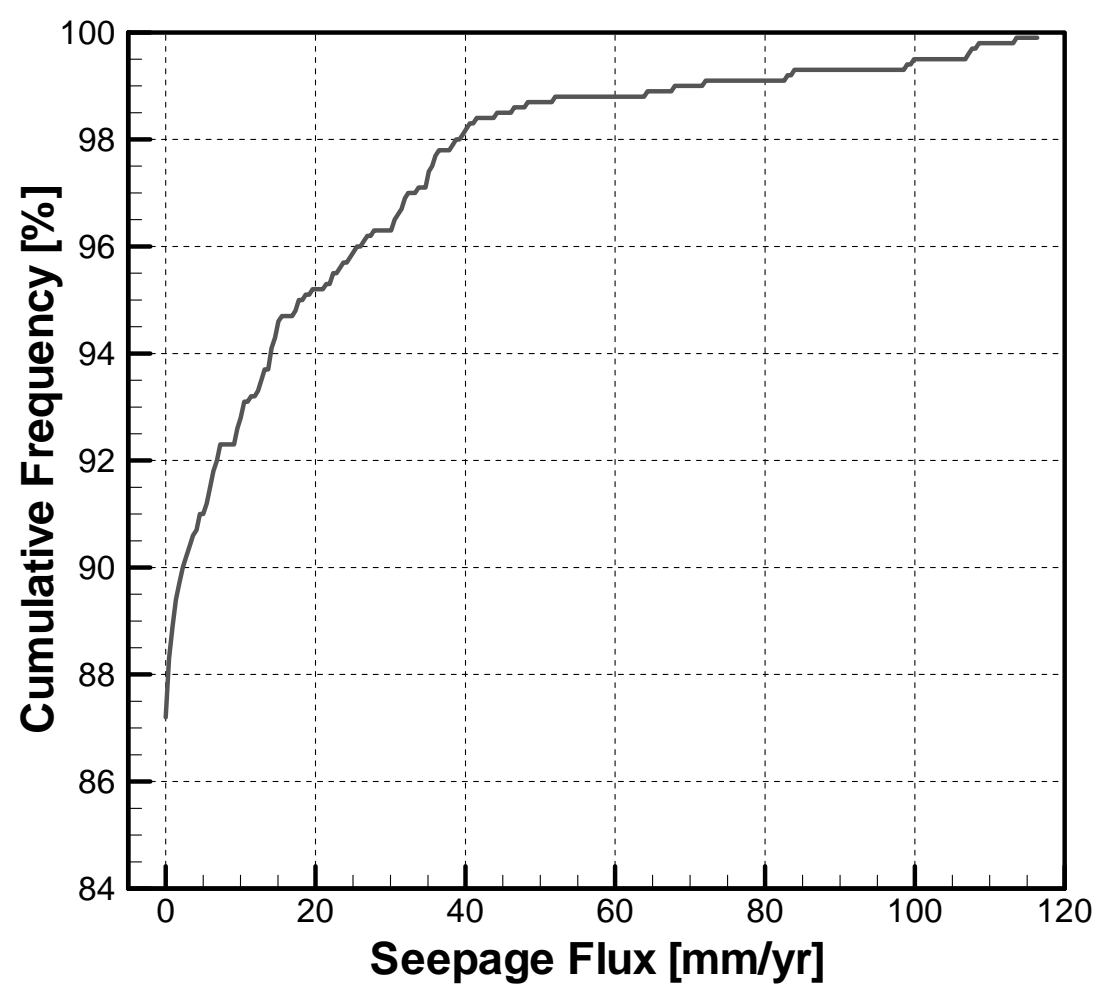

Figure 8. Cumulative distribution function of seepage flux averaged over the 5-month simulation period. Approximately $86 \%$ of the realizations did not yield any seepage; $5 \%$ of the realizations yielded seepage fluxes greater than approximately $18 \mathrm{~mm} / \mathrm{yr}$. 


\section{DISCUSSION}

This report describes preliminary predictions of seepage into the ESF South Ramp using an approach similar (but not identical) to that used in TSPA-LA. Rather than trying to analyze or reproduce the observed seepage data, the objective of this study was to examine whether the modeling approach employed to estimate seepage into waste emplacement drifts yields results that are consistent with the observations in the ESF South Ramp.

The seepage simulations yielded results that are not inconsistent with observations made in the South Ramp. Because both the observed data and the simulation results are highly uncertain and potentially biased, the following caveats must be considered when interpreting this result:

- The seepage observations are of qualitative nature. Specifically, it is not clear whether all the wet areas mapped in the ESF South Ramp (see Figure 1) actually lead to seepage as defined in TSPA-LA. Note that the actual dripping area is likely to be substantially smaller than the wet area. The current analysis makes the assumption that at least one dripping location is present for every $5 \mathrm{~m}$ of wet area along the drift axis. While the presence of puddles on the invert indicates dripping, water flow along the drift surface (as described for certain locations) does not constitute seepage. On the other hand, the size of the wet spots is known to strongly depend on evaporation rates, and dripping water may have evaporated before its detection. The estimated seepage fraction of approximately $13 \%$ is therefore highly uncertain.

- The seepage process model used as the basis for predicting seepage into the ESF South Ramp is consistent with that underlying the TSPA-LA seepage estimates. However, it makes the assumption that no evaporation occurs. While this assumption is conservative and appropriate for predicting long-term seepage into waste emplacement drifts under ambient conditions, it may not well represent the conditions in the ESF South Ramp. Accounting for evaporation effects would reduce the predicted seepage fraction.

- The seepage process model used for TSPA-LA is based on the assumption that the PTn dampens episodic infiltration events to yield near-steady percolation conditions in the Topopah Spring unit. In the absence of a porous PTn layer between the land surface and the ESF South Ramp, transient effects have to be taken into account. The model described here uses time-dependent flux boundary conditions and calculates transient seepage rates. However, it does not account for storage effects in the matrix. While such storage effects may be minor after a time period of 5 months, they may still impact seepage results, leading to a potential overestimation of seepage by the fracturecontinuum model.

- The seepage look-up table (visualized in Figure 5) and the Monte Carlo simulations are based on a single realization of the underlying small-scale permeability field. The analysis would have to be repeated for multiple realizations to obtain an estimate of the average behavior and to determine the prediction uncertainty. (Note that multiple realizations were analyzed for TSPA-LA.) The results from the single realization discussed here may therefore either over- or underestimate the mean seepage behavior. 
- The probabilistic seepage calculation presented in Section 3.3 is strongly affected by the distributions chosen to characterize uncertainty and spatial variability of the seepage-relevant parameters. While an effort has been made to obtain reasonable distributions, the following should be noted:

- Much less characterization data is available to describe the seepage-relevant hydrologic properties of the Tiva Canyon unit compared to those of the Topopah Spring unit, where the repository will be located. Specifically, there are no smallscale permeability data representative of the excavation-disturbed zone around the ESF, and no seepage experiments were performed in the Tiva Canyon unit to determine the seepage-specific capillary strength parameter.

- (Log)normal distributions were chosen in this study to describe the combined effect of uncertainty and spatial variability, while a combination of triangular, uniform, lognormal, and non-parametric distributions are used in TSPA-LA.

- There is currently no basis for the estimation of the infiltration flux, and thus no basis for the deterministic component of the local percolation flux. Given the importance of the local percolation flux for seepage calculations, detailed analyses combined with process model simulations are needed to estimate infiltration rates and percolation flux.

- TSPA-LA uses a combined deterministic-probabilistic approach to estimate the local percolation flux. Location-specific (i.e., deterministic) percolation fluxes are multiplied with a random (i.e., probabilistic) flow-focusing factor to arrive a local percolation fluxes used for seepage calculations. In this preliminary study for seepage into the ESF South Ramp, no location-specific percolation-flux estimates are available.

In summary, the modeling approach used to estimate long-term ambient seepage into waste emplacement drifts in the Topopah Spring unit has been minimally adapted to be able to estimate short-term, transient seepage into the ESF South Ramp located in the Tiva Canyon unit. Assuming probability distributions for fracture-continuum permeability, capillary strength, and local percolation flux, it was estimated that seepage would occur along about $12.8 \%$ of the ESF South Ramp. This estimate compares well with the observation that about $13 \%$ of the length of the ESF South Ramp exhibited wet spots in February 2005. However, the sensitivity of the model results to poorly constrained assumptions must be noted. To increase the confidence into these simulations, the infiltration flux must be determined for the hydrologic and topographic conditions at the land surface above the South Ramp, and the potential impact of evaporation in the ESF should be assessed. Nevertheless, these preliminary results seem to indicate that the seepage predictions made with the models and approach used in TSPA-LA are reasonable, even when applied to a different hydrogeologic unit and different hydrologic conditions. 


\section{RECOMMENDATIONS}

The observation of wet spots and seepage in the ESF South Ramp during and after a period of increased precipitation between October 2004 and February 2005 provides a unique opportunity to evaluate various submodels that were developed to predict the behavior of the unsaturated zone above the proposed nuclear waste repository at Yucca Mountain. This report is a preliminary attempt to test the suitability of the seepage process models and their abstraction for the estimation of seepage into large underground openings excavated from unsaturated, fractured tuff formations. In addition, the observations could be used to test other models supporting TSPA-LA, specifically the infiltration model, the UZ flow model, and the flow focusing model. Furthermore, the observations can be used to design monitoring and testing activities aimed at directly measuring natural percolation within Yucca Mountain. Knowing seepage locations along the ESF under natural conditions, a collection device can be designed that reduces or eliminates (1) capillary barrier effects and (2) evaporation. Percolation measurements could be made on various scales to examine flow partitioning between fractures and matrix, as well as flow channeling and flow focusing effects. If combined with a controlled infiltration experiment, valuable information about infiltration and percolation processes could be obtained. In addition, the seepage phenomena can be further evaluated, including evaporation and film flow effects.

We recommend the following experimental and modeling studies:

- Estimate infiltration above the ESF South Ramp using the current and an appropriately revised approach as a basis for unsaturated zone flow and seepage modeling.

- Estimate flow redistribution within the Tiva Canyon unit and local percolation flux above the ESF South Ramp using the current and an appropriately revised modeling approach.

- Examine the impact of potential evaporation on seepage predictions into the ESF South Ramp.

- Conduct probabilistic seepage predictions using revised distributions of the seepagerelevant parameters, specifically the local percolation flux.

- Examine all available data from the ESF South Ramp (specifically geochemical data) to improve understanding of infiltration, percolation, and seepage behavior.

- Design and install device for measuring natural percolation flux in the ESF South Ramp.

- Conduct infiltration tests at rates comparable to those during the October 2004 through February 2005 precipitation period; observe pattern and flow rates of percolation and seepage into the ESF South Ramp.

- Conduct detailed study of role of fracture geometry in unsaturated flow and seepage phenomena.

- Conduct comparative study of percolation and seepage conditions to explain absence of seepage observations in the ESF North Ramp; consider installing a bulkhead at the North Portal to reduce ventilation effects.

The proposed work will provide data that may significantly strengthen the confidence in process models and their abstraction for the evaluation of the natural barrier system at Yucca Mountain. 


\section{ACKNOWLEDGMENTS}

We would like to thank Rohit Salve and Joe Wang (LBNL) for their critical review comments. This work was supported, in part, by the Director, Office of Civilian Radioactive Waste Management, U.S. Department of Energy, through Memorandum Purchase Order QA-B004220RB3X between Bechtel SAIC Company, LLC and the Ernest Orlando Lawrence Berkeley National Laboratory (Berkeley Lab). The support is provided to Berkeley Lab through the U.S. Department of Energy Contract No. DE-AC02-05CH11231.

\section{REFERENCES}

BSC (Bechtel SAIC Company) 2004a. Seepage Model for PA Including Drift Collapse. MDLNBS-HS-000002 REV 03. Las Vegas, Nevada: Bechtel SAIC Company. ACC: DOC.20040922.0008.

BSC (Bechtel SAIC Company) 2004b. Abstraction of Drift Seepage. MDL-NBS-HS-000019 REV 01. Las Vegas, Nevada: Bechtel SAIC Company. ACC: DOC.20041103.0003.

BSC (Bechtel SAIC Company) 2004c. Seepage Calibration Model and Seepage Testing Data. MDL-NBS-HS-000004 REV 03. Las Vegas, Nevada: Bechtel SAIC Company. ACC: DOC.20040922.0003.

BSC (Bechtel SAIC Company) 2004d. UZ Flow Models and Submodels. MDL-NBS-HS000006, Rev. 02. Las Vegas, Nevada: Bechtel SAIC Company.

BSC (Bechtel SAIC Company) 2004e. Simulation of Net Infiltration for Present-Day and Potential Future Climates, MDL-NBS-HS-000023, Rev. 00. Las Vegas, Nevada: Bechtel SAIC Company

BSC (Bechtel SAIC Company) 2004f. Calibrated Properties Model. MDL-NBS-HS-000003, Rev. 02. Las Vegas, Nevada: Bechtel SAIC Company.

BSC (Bechtel SAIC Company) 2005. White Paper: ESF South Ramp Water Seepage During February-May 2005. Draft 5/16/2005.

LBNL (Lawrence Berkeley National Laboratory) 2002. Software Code: iTOUGH2. V5.0. SUN UltraSparc., DEC ALPHA, LINUX. 10003-5.0-00. 